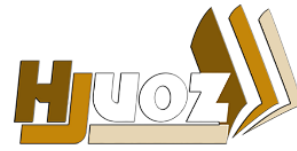

hjuoz.uoz.edu.krd p-ISSN: 2410-7557
كَّوارا زانستيّن مروّقايهتى يا زانكوّيا زاخوّ

مجلة العلوم الانسانية لجامعة زاخو

Humanities Journal of University of Zakho (HJUOZ)

Vol. 6, No. 3, pp. 837-849, Sept.-2018

\title{
واقع البحث التربوي ومشكلاته من وجهة نظر التدريسيين التربويين في جامعة دهوك
}

صابر عبد الله سعيد" و بشكوش جعفر عبدالله

مدير مركز البحوث التربوية، جامعة دهوك، اقليم كردستان - العراق.

كلية التربية الاساسية، جامعة دهوك، اقليم كردستان - العراق.

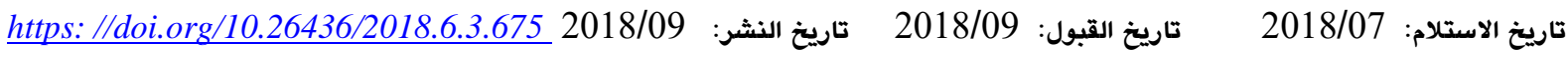

الملخص:

يهدف البحث الحالي إلى التعرف على ما يأتي:

1. أهم المشكلات التي تواجه الباحثين التربويين في جامعة دهوك.

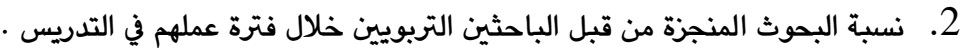

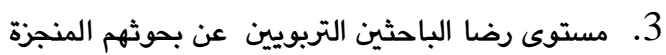

4. الغرض (الهدف) من إنجاز البحوث (هل هي للترقية العلمية فقط أم رغبة في حل المشكلات التي تواجه العلمية التربوية وغيرها). و لغرض تدقيق اهداف البحث تم إتباع المنهج الوصفي المسحي, و تم إعداد أداة للبحث على شكل إستبانة من النوع المغلق المفتوح

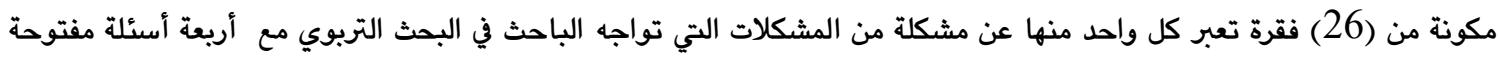

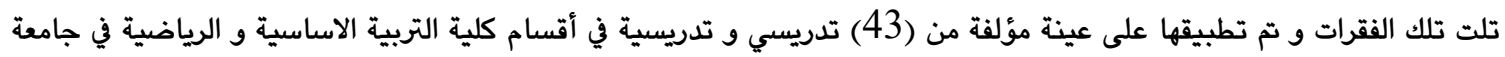
دهوك و بعد تحليل البيانات إحصائياً باستخدام قانون الوسط المرجح لاستخراج حدة (قوة) الفقرات أظهرت النتائج أن جميع فقرات

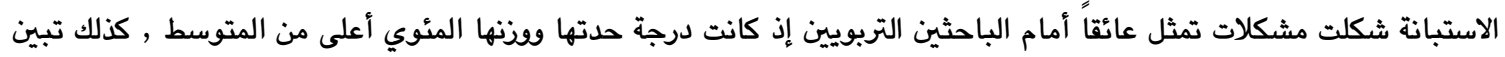

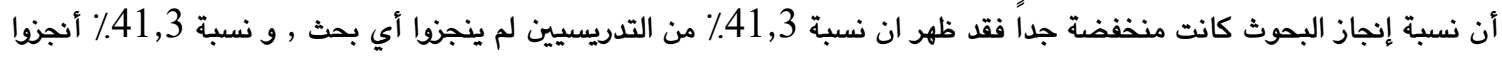

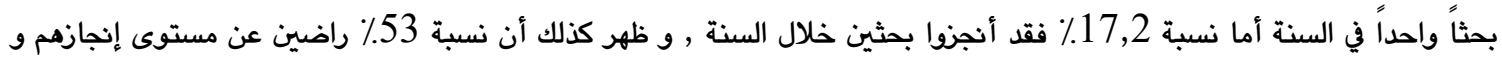
بالمقابل 47٪ غير راضين , أما عن الغرض من إنجاز البحوث كان للترقية العلمية بنسبة 63٪ قد أنجزوا البحوث لغرض الترقية

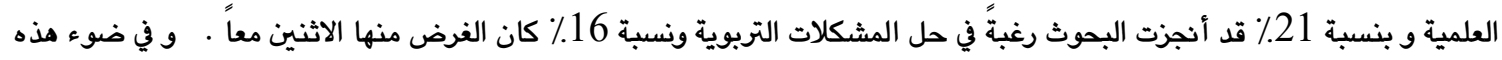
النتائج خرج الباحثان بمجموعة من التوصيات و المقترحات لغرض النهوض بواقع و مستوى إنجاز البحوث التربوية في جامعة دهوك . الكلمات الدالة: الباحثين التربويين، البحث التربوي، جامعة دهوك.

ضمنه إقليم كوردستان لم تتوفر أي معلومات عن نسبة الانفاق على UNESCO SCIENCE REPORT, ) البحث العلمي

(2010,61

و تعد الجامعات من المراكز الرئيسية للبحث العلمي فمن اهدافها الرئيسية إعداد قوى بشرية ,البحث العلمي , التنشيط الثقافي العام

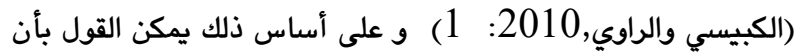
مهام التدريسي الجامعي لا تختصر على إلقاء المحاضرات و الاطلاع على التطورات الحاصلة في العالم بل يتعداه الى امتلاك مهارات بحثية تمكنه من البحث و تقصي الحقائق . وعليه فإن من واجب المؤسسات الاكاديمية أن تضع البحث العلمي في قائمة اولوياتها و تحرص على تطويره و تهيئ و تمهد الطريق أمام كوادرها لإجراء بحوث تخدم قضايا و حاجات المجتمع و تساهم في حل مشكلاته ولكن رغم ذلك يبدوا ان

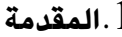

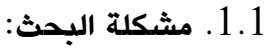

من الواضح ان من أبرز سمات العصر الحالي هو مدى التطور السريع و المضطرد في كافة مجالات الحياة العلمية و الاقتصادية و الاجتماعية

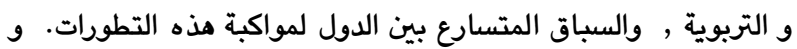
لا يخفى على أحد ما للبحث العلمي من دود و أهمية في هذا التطور لذلك نرى أن الدول المتقدمة أدركت هذه الاهمية و الدود و أولت اهتماما

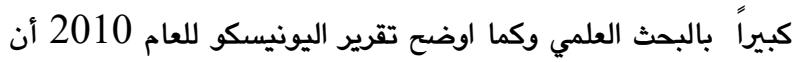
الدول المتقدمة خصصت له ميزانيات مائلة تفوق ميزانيته كل المؤسسات الاخرى في المجتمع و دعمهم الكبير للمؤسسات البحثية و الباحثين في حيث الانفاق الكبير و الكادر المتقدم و مستوى أكبر بكثير مما مو معتمد في الدول النامية و الدول العربية و بالنسبة للعراق و من 
و لما كانت الوظيفة الاساسية للبحث هي "تقدم المعرفة" من أجل

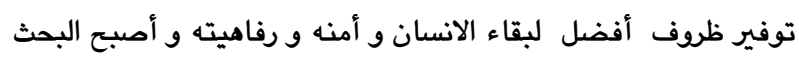

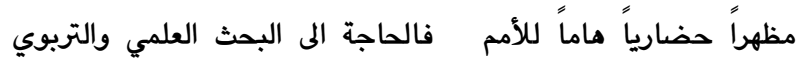

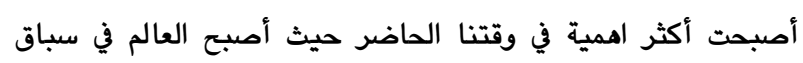

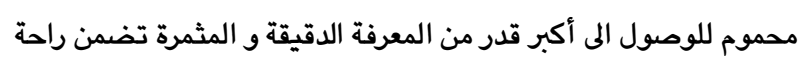

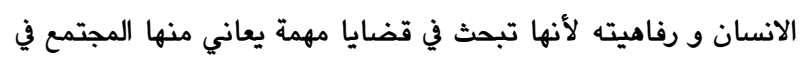

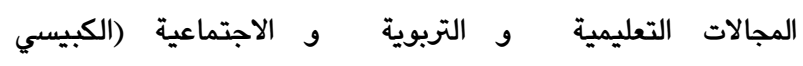
والراوي,2010: 2-3 (الكيلاني و الشريفين ,2007: 16 16).

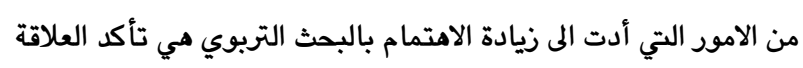

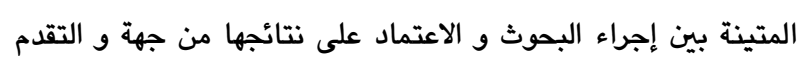

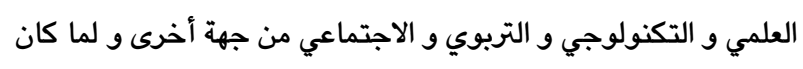

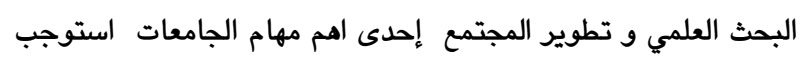

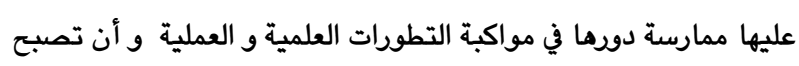
أداة فعالة من أدوات التغيير و التطود في المجتمع (العزاوي,2008:

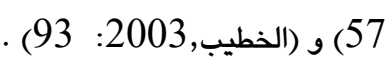

ويناءً على ما سبق يمكن تحديد أهمية البحث الحالي بالنقاط الاتية :

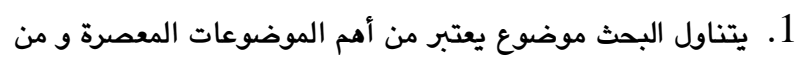

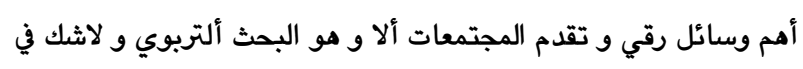

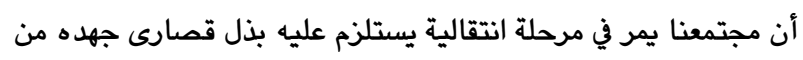
أجل ضمان مستقبل مشرق للإنسان الكوردي و وتقدمه.

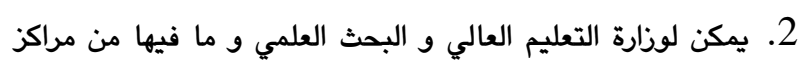

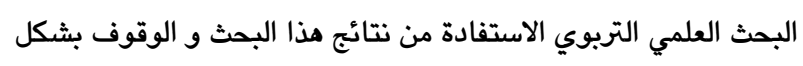

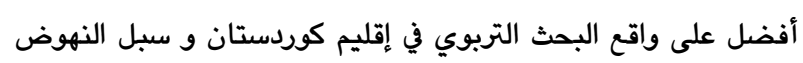

3. ستساعد أداة و نتائج و توصيات هذا البحث المهتمين بالبحث

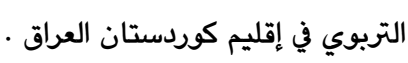

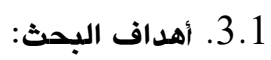

يهدف البحث الحالي إلى التعرف على ما يأتي: 1. أهم المشكلات التي تواجه الباحثين التربويين في جامعة.

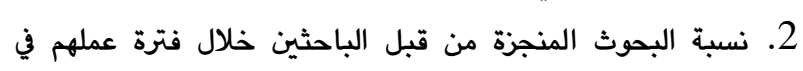
التدريس.

3. مستوى رضا الباحثين التربويين عن البحوث المنجزة

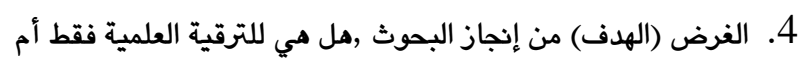
رغبة في حل المشكلات التي تواجه العلمية التربوية.

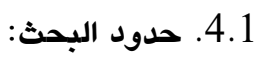

يقتصر البحث الحالي على التدريسيين التربويين في كليتي التربية

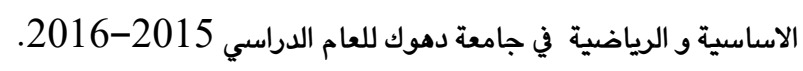

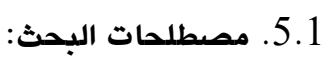

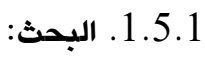
1. تعريف عبدالحميد (1.1.1 البحث:
حركة البحث العلمي في الدول النامية في الشرق الاوسط تعاني من حالة

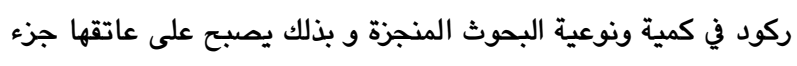

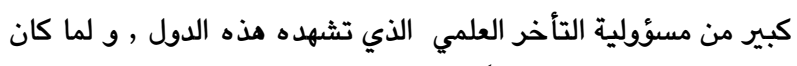

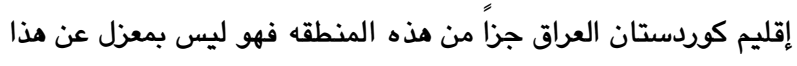

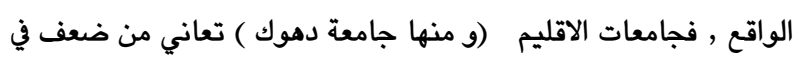

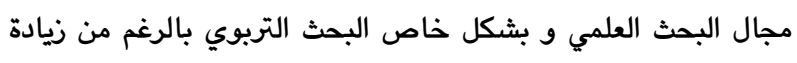
عددها في السنوات الاخيرة حيث كثرت عدد الجامعات في الاقليم بصورة

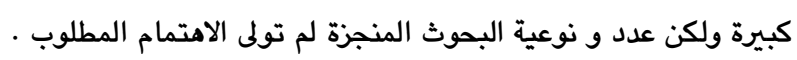

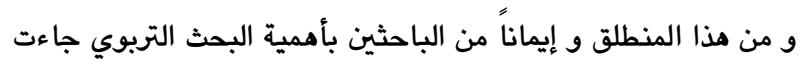

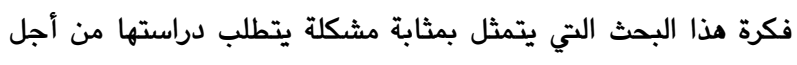

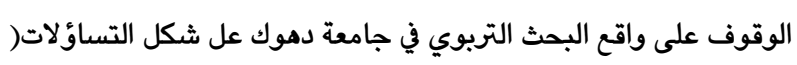

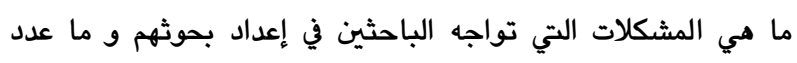

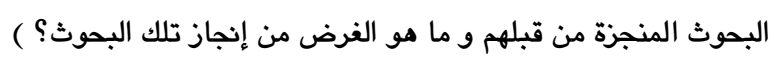

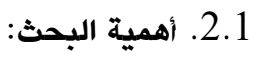
يمثل البحث العلمي ركناً أساسياً في حياة الامم و الشعوب , و جزءاً

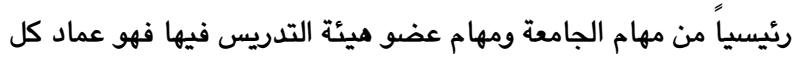
تخطيط و عصب كل تنمية إذ بواسطته يتم وضع خطط التنمية على

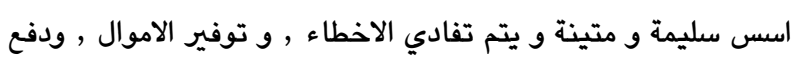
الخسائر , وتقصير الزمن و تحسين النوعية (البرغوثي و ابو سمرة (2007, و تبرز أهمية البحث (العلمي) بازدياد اعتماد الدول عليه إدراكاً منها

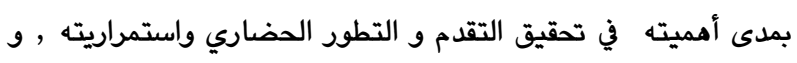

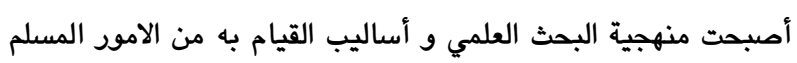

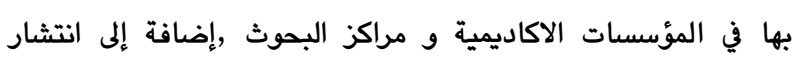
استخدامها في معالجة المشكلات التي تواجه المؤسسات العامة و الخاصة على حد سواء (ملحم, 2005: 47-48). و تشكل مؤسسات التعليم العالي أهم المراكز العلمية التي تناط بها

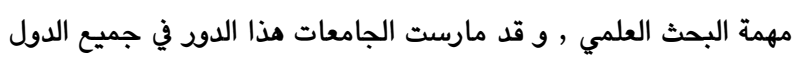

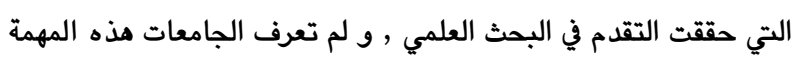

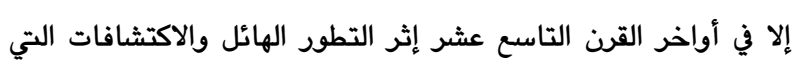

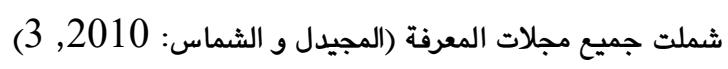
ويعد البحث التربوي جزءاً من البحث العلمي , فهو يستند الى المبادئ

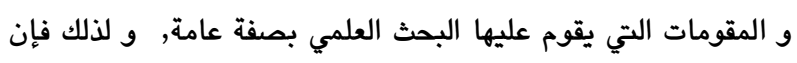

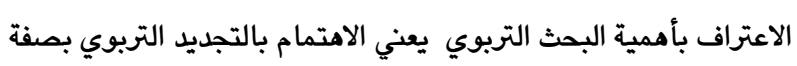

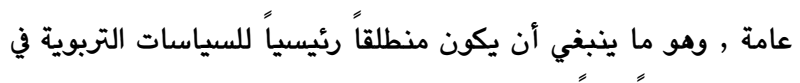

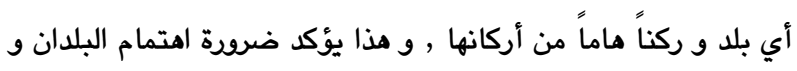
خاصة الشرق أوسطية بالبحوث التربوية و إعطائها الاولوية التي تستحقها و توفير ما تحتاجه من الامكانيات المادية و البشرية (ابراهيم و ابو زيد , 2007: 2: و (نوافلة ,2011: 1 1). 
الاستفادة من بعض إجراءات تلك الدراسات في الدراسة الحالية و كما

1 ( معوقات البحث العلمي في جامعة القدس المفتوحة و دور الجامعة في تطويره) هدفت هذه الدراسة الى تشخيص المعوقات التي تواجه البحث العلمي و

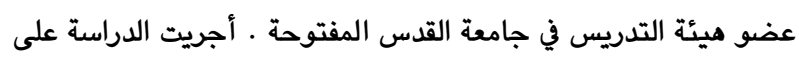
عينة مؤلفة من (132) فرداً من أعضاء هيئة التدريس في جامعة القدس

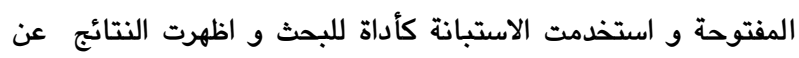
وجدود العديد من المعوقات تتعلق بالنواحي الادارية و التنظيمية و النشر و التوزيع والتي تدد من إجراء البحث العلمي ( الجرجاوي و حمادة ,2005: 2 3) 2. دراسة المجيدل و الشماس 2010 ( معوقات البحث العلمي في كلية التربية من وجهة نظر أعضاء الهيئة التدريسية كلية التربية بصلالة أنموذجا هدفت هذه الدراسة الى تقصي المعوقات التي تواجه أعضاء الهيئة التدريسية في كلية التربية بصلالة و تحول دون إنجازهم لأبحاث علمية , و سبل التغلب على هذه المعوقات . تكونت عينة البحث من كافة أعضاء الهيئة التدريسية في كلية التربية و استخدمت الاستبانة كأداة للبحث كما أستخدم برنامح SPSS في إستخراج و تحليل النتائج والتي اظهرت ان المعوقات الادارية هي أشد المعوقات و عدم وجود فروق ذو دلالة إحصائية حسب متغير الجنس و التخصص , بينما ظهرت فروق ذو دلالة إحصائية حسب متغير سنوات الخدمة(المجيدل و

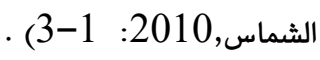
3. دراسة الكبيسي و الراوي 2010 (الانتاج العلمي لأعضاء هيئة التدريس في جامعة الانبار من البحوث العلمية و معوقاتها للتخصصات الانسانية ) هدفت هذه الدراسة الى التعرف على الانتاج العلمي لأعضاء ميئة التدريس في جامعة الانبار و المعوقات التى تقع في طريق إنجاز البحوث العلمية. بلغت عينة البحث (61) من أعضاء الهيئة التدريسية من الكليات الانسانية في جامعة الانبار, و استخدمت الاستبانة أداةً للبحث

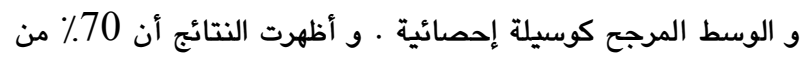

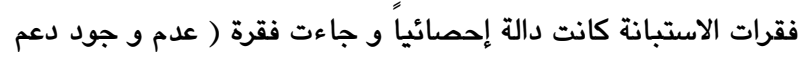
مادي ) في المرتبة الاولى و( انعدام(ضعف) الدعم لحضور المؤتمرات الاقليمية و العالمية ) جاءت في المرتبة الثانية , كما أظهرت النتائج أن الن النائ مستوى الانتاج العلمي لأعضاء الهيئة التدريسية في الجامعة المذكورة

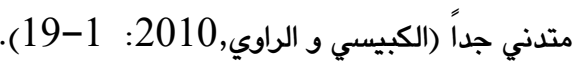
4. دراسة محسن 2011 ( الصعوبات التي تواجه البحث العلمي في جامعة بغداد من

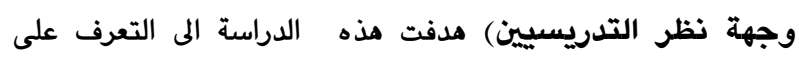

البحث هو نشاط علمي منظم يسعى إلى الكشف عن الحقائق و معرفة الارتباط بينها و أستخلاص المبادىء العامة و القوانين التفسيرية. عبدالحميد, 8: 2000) 2. تعريف العواودة (2002) هو وسيلة للدراسة يمكن بواسطتها الوصول إلى حل لمشكلة محددة وذلك عن طريق الاستقصاء الشامل و الادلة التي يمكن التحقق منها والتي تتصل بتلك المشكلة المحددة. (العواودة, 2002: 20) 3. تعريف ملحم (2005) هو عملية منظمة تهدف الى التوصل الى حلول لمشكلات محددة , او الاجابة عن تساؤلات معينة باستخدام أساليب علمية محددة يمكن أن

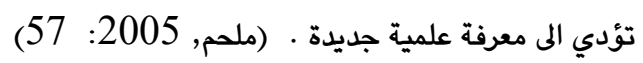

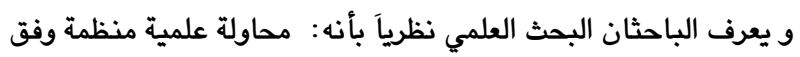
منهجية وإجراءات علمية محددة لغرض تقصي الحقائق المتعلقة بمشكلة معينة في أي ميدان من ميادين المعرفة من أجل أيجاد حلول لتلك المشكلة. 2.5.1 1. تعريف عدس (1997) هو أحد ميادين البحث العلمي المختلفة, ومو يسعى بحكم تسميته إلى التعرف على المشكلات التربوية و أيجاد الحلول المناسبة لها .

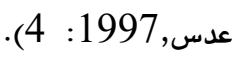
2. تعريف منسي (1999) هو جهد علمي منظم و موجه لغرض التوصل إلى حلول للمشكلات التربوية (منسي, 1999, 12). 3. تعريف ملحم (2005) (مينسئ هو دراسة تطبيقية يقوم بها الباحثون العاملون في مجال العمل المدرسي,للتحقق من اكتسابهم لواحدة من الكفايات الاساسية الضرورية لتأدية عملهم(ملحم ,2005: 7 ) ويعرف الباحثان البحث التربوي نظرياً بأنه عملية التقصي وفق منهج و إجراءات علمية للوقوف على المشكلات التربوية لكل مجالاته المتعلقة بالمدرس و الطالب و المنهج و الامتحانات و الادارة و غيرها و التوصل إلى سبل المعالجة لها. أما التعريف الاجرائي فيتمثل باستجابات ودرجات أفراد عينة البحث على فقرات أداة البحث التي سيتم إعداده فيما بعد .

\section{2. - 2. الدراسات السابقة}

نظراً لكون البحث يتناول المشكلات التي تواجه التدريسيين في مجال البحث التربوي وكون ان مفهوم المشكلة و طبيعتها من المفاهيم العامة

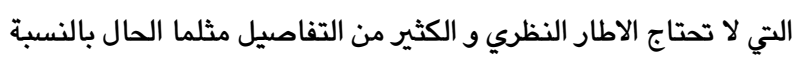
للمفاهيم و المتغيرات العلمية و النفسية الاخرى لذا سيتم ذكر عدد من الدراسات السابقة التي تناولت موضوع مشكلات البحث العلمي لغرض ولمريك 
بعد أن تم عرض الدراسات السابقة المذكورة تم مناقشتها لغرض الاستفادة من بعض إجراءات تلك الدراسات في دراستنا الحالية و خاصة المتعلقة بالأهداف و إعداد الاداة و اختيار العينة و الوسائل الاحصائية المناسبة لطبيعة البحث الحالي. وعند المقارنة بين اهداف و اجراءات و نتائج البحث الحالي ظهر تفرده عن تلك الدراسات.

\section{4. منهجية وإجراءات البحث}

يتضمن هذا الجزءمن البحث على عرض لمنهج و إجراءات البحث من حيث المجتمع و العينة و أداة البحث و كيفية تطبيقها و الوسائل

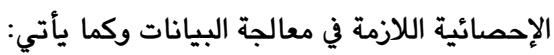

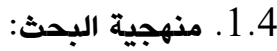
سيتم الاعتماد على المنهج الوصفي المسحي لكونه من أكثر مناهج البحث التربوي ملائمة لطبيعة وأهداف البحث الحالي. 2.4. مجتمع عينة البحث: شمل مجتمع البحث جميع التدريسيين (مدرسين و مدرسات) الحاصلين على شهادة الماجستير أو الدكتوراه او من المراتب العلمية مدرس مساعد فأعلى في الاختصاصات التربوية و النفسية وطرائق التدريس والبالغ عددمم (49) تدريسي و تدريسية موزعين على الاقسام التربوية المتمثلة بقسم التربية و علم النفس و التربية الخاصة ورياض الاطفال في كلية التربية الاساسية والتدريسيين التربويين في كلية التربية الرياضية ولية في جامعة دموك و الجدول (1) يوضح ذلك . الجدول (1): مجتمع البحث

\begin{tabular}{|c|c|c|c|}
\hline 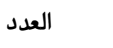 & 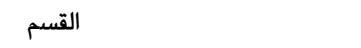 & الكلية & $ت$ \\
\hline 17 & التربية وعلم النفس & \multirow[t]{3}{*}{ التربية الاساسية } & .1 \\
\hline 09 & التربية الخاصة & & \\
\hline 13 & رياض الاطفال & & \\
\hline 10 & التدريسيين التربويين وطرق التدريس & التربية الرياضية & .2 \\
\hline 49 & 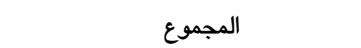 & & \\
\hline
\end{tabular}

و تدريسية بعد استبعاد (6) من التدريسيين المجازين أو المعارين أو 3.4. عينة البحث: المسافرين و بذلك أصبحت عينة البحث تمثل مجتمع البحث بنسبة

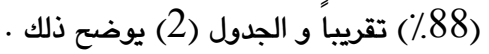

الصعويات التي تواجه البحث العلمي في جامعة بغداد من وجهة نظر التدريسيين و التعرف على الفروق في نظرتهم لهذه الصعويات حسب اعتمدت على الاستبانة كأداة للبحث و أستخدم قانون الوسط المرجح و الاختبار التائي لعينتين مستقلتين T.test كوسيلة إحصائية. أظهرت النتائج وجود معوقات مرتبطة بالجانب المادي و الفني و و التنظيمي ت تؤثر بشكل كبير على حركة البحث العلمي في جامعة بغداد و عدم وجود فروق ذات دلالة إحصائية حسب متغير التخصص

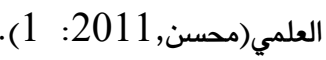
5. دراسة البومحمد و البدري 2012 ( واقع البحث العلمي في العالم العربي و معوقاته)

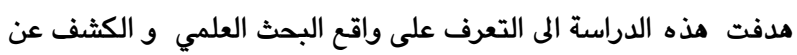
أبرز المعوقات التي تحد من إجراء البحوث العملية في ضوء الدراسات السابقة ذات العلاقة و اقتراح الحلول المناسبة لها. وأظهرت نتائج البحث ان البحث العلمي في العالم العربي لا يزال ضعيفاً و يواجه جملة من المعوقات تتمثل بانفصال البحث العلمي عن المجال التطبيقي و تدني نسب الانفاق بشكل ملفت و عدم توفر قاعدة معلومات و غياب المصادر العلمية( البومحمد و البدري,2012: 1 1). 3. مناقثة الدراسات السابقة متغير التخصص العلمي. و تألفت عينة البحث من (225) فرداً , و و 


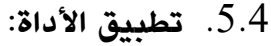

بعد أن أصبحت ألأداة جاهزة للتطبيق قام الباحثان بنفسيهما بتطبيقها

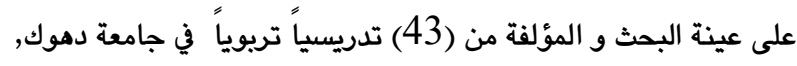

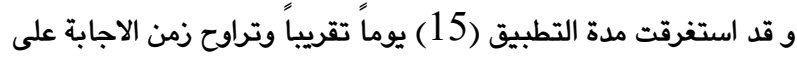

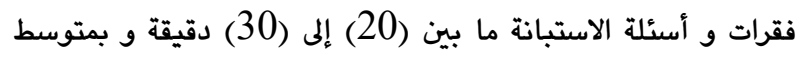

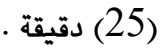

6.4. تصحيح الاجابات: بعد الانتهاء من تطبيق اداة البحث على أفراد عينة البحث تم تصحيح

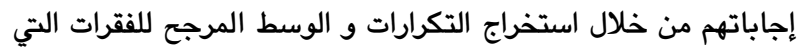
تمثل مشكلات البحث التربوي باستخدام معادلة فيشر و استخراج التكرارات و النسب المئوية و نسبة واتفاق على اجابات الاسئلة الثلاثة

\section{المفتوحة التي تلت تلك الفقرات .}

7.4 الوسائل الإحصائية:

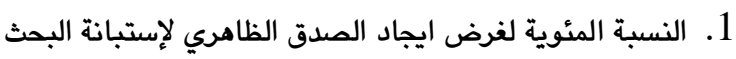
1. الوسط المرجح (درجة الحدة) لغرض ايجاد حدة (قوة) الفقرات

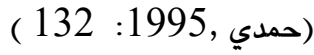

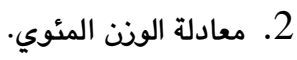

\section{5رض النتائج و مناقشتها}

1.5. يتضمن هذا الجزء من البحث على عرض لنتائج البحثو مناقشتها في ضوء الأهداف وكما ياتي:

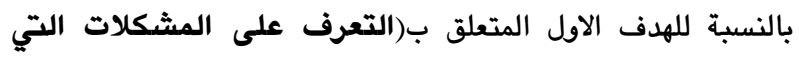

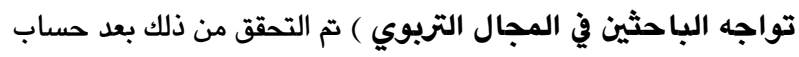
التكرارات و إستخراج حدة (قوة) الفقرات و اوذانها المئوية باستخدام

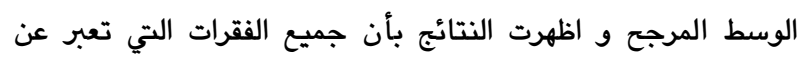

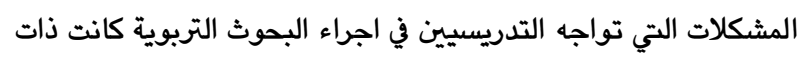

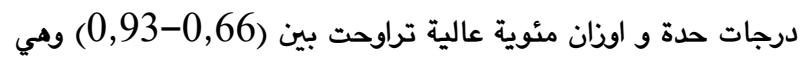

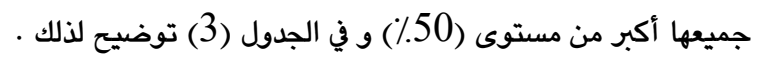

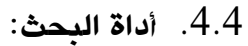

لغرض التحقق من أهداف البحث تطلب وجود أداة و بعد إطلاع الباحثَّين

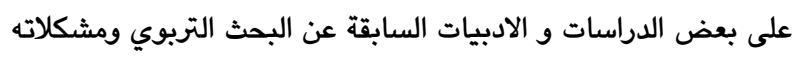

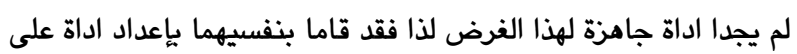

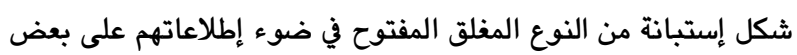

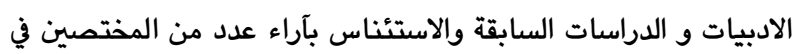
المجال التربوي وخبرة البحثان انفسهم في مجال البحوث التربوية تم

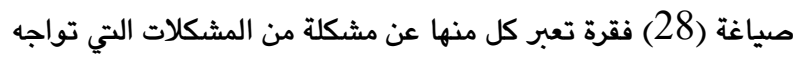

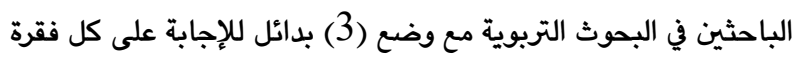

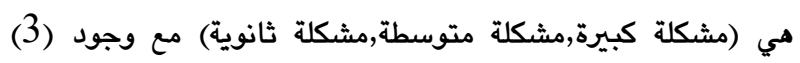

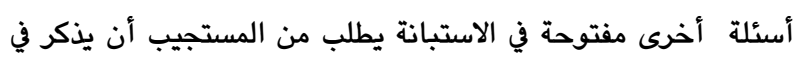
السؤال الاول عدد البحوث المنجزة من قبله خلال سنوات عمله في التدريس وأن يذكر في السؤال الثاني مدى الرضا لديه عن البحوث من فيل المنجزة من حيث مستواها ومدى الاستفادة منها و ان يذكر في السؤال الثالث الغرض او الهدف من إنجازه للبحوث التربوية و بذلك أصبحت التحت الاداة مؤلفة من (26) فقرة مغلقة مع (3) أسئلة مفتوحة. ولغرض زيادة التأكد من صلاحية الاستبانة لقياس أهداف البحث الحالي تم استخراج الخاصية السايكوميترية الاكثر أهمية للأداة عندما يكون استبياناً و المتمثلة بالصدق والتي تعني ببساطة مدة استطاعة الاداة

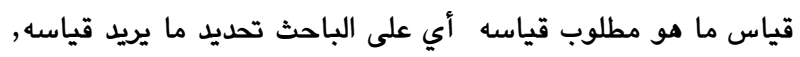
فإذا حققت الأداة الغرض الذي يستهدفه الباحث فإنها بذلك تكون

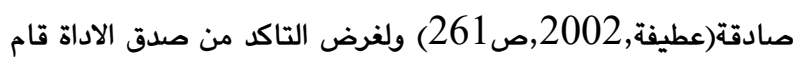

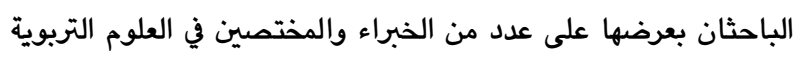
و النفسية و القياس النفسي وبعد الطلاع على ارائهم و بالاعتماد على

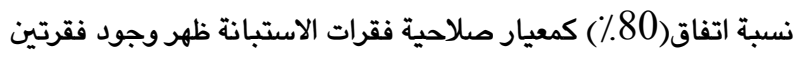

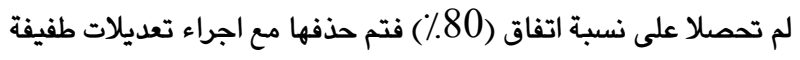

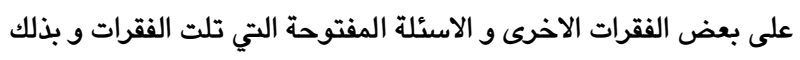
اصبحت الاداة مؤلفة بشكلها النهائي من (26) فقرة و (3) أسئلة مفتوحة و جاهزة للتطبيق كما مبين في الملحق (2) . الجدول ( 3 ) : يبين الفقرات ذات درجة حدة و أوذان مئوية أعلى من المتوسط

\begin{tabular}{|c|c|c|c|c|}
\hline 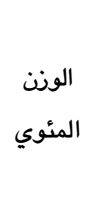 & 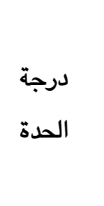 & الفقرات (المشكلات) & الالفقرة في & الحئ وفقاً لدرجة \\
\hline 0,93 & 2,804 & الاقليم تشجيع الجامعة للتدريسيين على الحضود و المشاركة في المؤتمرات العلمية و خاصة خارج & 19 & .1 \\
\hline 0,92 & 2,760 & تأخر نشر الابحاث في مجلm جامعتنا & 1 & .2 \\
\hline 0,90 & 2,717 & تأخر الخبراء في تقويم البحوث لأغراض النشر و الترقية & 7 & .3 \\
\hline 0,90 & 2,717 & قلبحث التنسيق بين الجامعة و مؤسسات المجتمع المحلي لغرض التعرف على مشكلاتهم و إجراء & 4 & .4 \\
\hline
\end{tabular}


سعيد، صابر عبد الله و عبدالله، بشكوش جعفر / مجلة العلوم الانسانية لجامعة زاخو، مجلد:6 ، العدد:3 ، ص 837- 849، ئيلون- 2018.

\begin{tabular}{|c|c|c|c|c|}
\hline 0,90 & 2,695 & قلة الدعم المادي و المعنوي للباحثين في المجال التربوي & 12 & 5 \\
\hline 0,89 & 2,673 & عدم التنسيق بين جامعتنا و الجامعات العالمية لغرض نشر الابحاث في مجلاتهم & 10 & .6 \\
\hline 0,86 & 2,586 & قلة عقد المؤتمرات العلمية و عدم نشر أبحاث المشاركين في اعداد خاصة بالمؤتمر & 11 & .7 \\
\hline 0,86 & 2,586 & عدام وجود مختبر علمي لعلم النفس لإجراء الدراسات التجريبية عن الموضوعات النفسية و & 23 & .8 \\
\hline 0,85 & 2,565 & و الجامعة اعتماد عدد البحوث المنجزة خلال السنة كمعيار أساسي لتقويم التدريسي من قبل القسم & 18 & .9 \\
\hline 0,85 & 2,565 & عدم تشجيع قيام البحث الجماعي في مجال البحوث التربوية & 9 & .10 \\
\hline 0,85 & 2,565 & ] [ [عدم تعاون بعض الجهات الادارية مع الباحثين لإنجاز أبحاثهم & $2 \square$ & .11 \\
\hline 0,84 & 2,543 & عدم الاستفادة والأخذ بنتائج الابحاث و التوصيات و المقترحات التي تتوصل اليها & 8 & .12 \\
\hline 0,84 & 2,543 & قلة إيفاد الباحثين خاصة في المجال التربوي إلى الخارج & 26 & .13 \\
\hline 0,84 & 2,543 & ضعف المنافسة بين التدريسيين في إنجاز البحوث و عدم تقويمهم على أساس ذلك . & 17 & .14 \\
\hline 0,82 & 2,478 & زيادة اهتمام الجامعة ببحوث الاختصاصات العلمية للعلوم الصرفة أكثر من البحوث التربوية & 22 & .15 \\
\hline 0,81 & 2,456 & ضعف خبرة و معلومات بعض التدريسيين عن إجراءات و مناهج البحث العلمي & 20 & .16 \\
\hline 0,81 & 2,456 & أثر المرغوبية الاجتماعية ( عدم صدق المستجيبين الذين تطبق عليهم الاستبانة) على نتائج & 25 & .17 \\
\hline 0,79 & 2,391 & صعوية توصل الباحث الى المجتمع و العينة اللازمة لإنجاز البحوث التربوية و النفسية عليهم & 24 & .18 \\
\hline 0,78 & 2,369 & 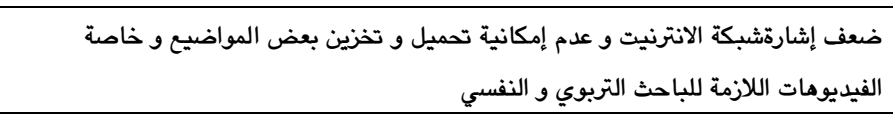 & $14 \square$ & .19 \\
\hline 0,77 & 2,326 & كثرة انشغال التدريسيين بمتطلبات ضمان الجودة & 3 & .20 \\
\hline 0,77 & 2,326 & التربوية عليهم إستجابة بعض الافراد مع الباحثين في تطبيق الاستبيانات و المقاييس اللازمة للبحوث & 13 & .21 \\
\hline 0,76 & 2.304 & قلة عدد الممادر والمجلات المتوفرة في جامعتنا وخاصة للاختصاصات التربوية و النفسية & 6 & .22 \\
\hline 0,72 & 2,173 & انشغال معظم التدريسيين بمتطلبات ظروف الحياة و قيامهم بأعمال أخرى & 15 & .23 \\
\hline 0,66 & 2 & قلة الدافعية و الرغبة في إنجاز البحوث و الاكتفاء بالتدريس & 16 & .24 \\
\hline 0,66 & 2 & تكليف التدريسي بعدد كبير من ساعات التدريس (المحاضرات الاسبوعية) للدوامين الصباحي & 5 & .25 \\
\hline 0,66 & 2 & قلة أدوات القياس من الاختبارات و المقاييس اللازمة لإنجاز البحوث التربوية و النفسية & 21 & .26 \\
\hline
\end{tabular}

المؤتمرات العلمية و خاصة خارج إقليم كوردستان) وهذا يشكل عقبة في سبيل التطور و التقدم في مجال البحوث التربوية و النفسية لأنه من

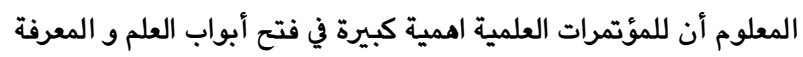
يساعد الباحث على التعرف على كل ما مو جديد و معاصر في مجال 842
ومن خلال النظر الى النتائج في الجدول السابق نرى أن المشكلة التي حصلت على ونن مئوي اعلى و جاءت بالمرتبة الأولى من بين جميع

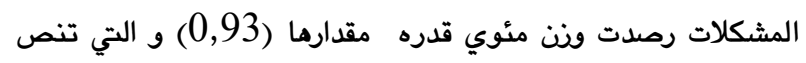
على (عدم تشجيع الجامعة للتدريسيين على الحضور و المشاركة في 
اما بالنسبة للمشكلات الاخرى ذات الاوذان المئوية الاقل يمكن عرضها و مناقشتها بشكل عام و منها عدم تعاون الجهات و المؤسسات التي تجري البحوث التربوية على منتسبيها مع الباحث و مشكلة اخرى يحس بها الباحث التربوي هو اهتمام الجامعة بالبحوث العلمية أكثر من البحوث

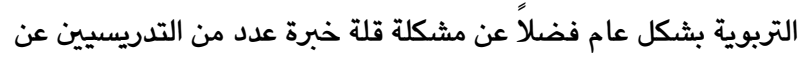
مناهج و إجراءات البحث التربوي و عدم امكانية الباحثين على الحصول على المصادر و المعلومات اللازمة لبحثهم و بشكل خاص وجود مشكلة ضعف استخدام شبكة الانترنيت و عدم القدرة على الحصول على المعلومات بسبب خلل او ضعف شبكة الانترنيت أو طلب مبالغ مادية من بعض المواقع الالكترونية وكذلك كثرة انشغال التدريسيين بالمحاضرات خلال اليوم الدراسي والانشغال بمتطلبات ظروف الحياة اليومية الناتجة عن الازمات و الظروف الصعبة في وقتنا الحالي والتي تؤدي إلى ضعف الدافعية والرغبة في انجاز البحوث التربوية بشكل خاص مع وجود مشكلة قلة أو عدم توفر أدوات القياس المتمثل بالاختبارات و المقاييس الازمة لتحقيق أهداف البحوث التربوية وقلة خبرة معظم التدريسيين في بناء تلك المقاييس و الاختبارات بشكل علمي دقيق. و اخيراً يواجه الباحث في البحث التربوي والنفسي بشكل عام عدم التعاون من قبل أفراد مجتمع وعينة البحث في الاجابة على أدوات البحث و الذي يدل على عدم أو قلة الوعي لدى أفراد مجتمعنا بقيمة و اهمية البحوث التربوية و ما يتمخض عن نتائج واستنتاجات مهمة للإنسان و

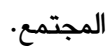
وعند المقارنة بين نتائج البحث الحالي مع نتائج الدراسات السابقة ظهر وجود اتفاق نسبي في بعض الفقرات بشكل عام مع اختلاف مع نتائج بعض تلك الدراسات في فقرات أخرى وخاصة المتعلقة بالإجابة على بلى بعل الاسئلة المفتوحة التي تلت الفقرات في أداة البحث الحالي والتي تؤكد تفرد البحث الحالي و حداثته في مذا المجال .

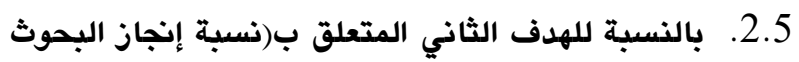
التربوية في جامعة دهوك): أظهرت نتائج البحث بأن نسبة 41,3\% من التدريسيين لم ينجزا أي

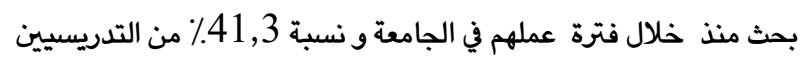

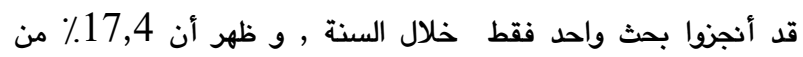

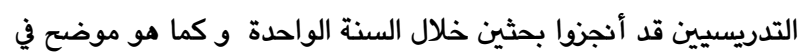

الجدول (4) (4) - (4)
البحث العلمي التربوي و تمكنه من التعرف على باحثين اخرين من الدول و الجامعات الاخرى و يستفاد من خبرتهم أو قد تمكن الباحث من إنجاز بحوث مشتركة معهم و نشرها في مجلات علمية عالمية . وجاءت مشكلة( تأخر نشر الابحاث في مجلة جامعتنا) بالمرتبة الثانية بونن مئوي قدره ( 0,92) و في المرتبة الثالثة جاءت مشكلة (تأخر تقويم البحوث) بونن مئوي مقداره (0,90) حيث إن تأخر نشر و تقويم البحوث مشكلة قوية أخرى تقف في وجه الباحث التربوي حيث إذ يقلل من عزمه و حماسه في المضي قدماً لإنجاز بحوث أكثر و الترقية

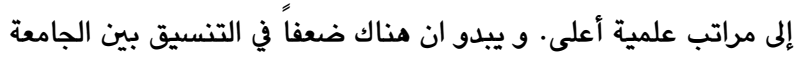
و مؤسسات المجتمع هي الاخرى مشكلة تؤثر على إنجاز البحوث

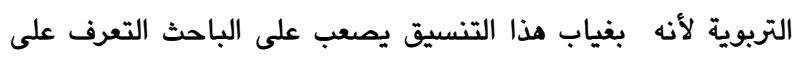
المشكلات التي يعاني منها المجتمع و التي تستلزم دراستها بعمق و موضوعية , و إذا لم يتمكن الباحث من الحصول على دعم مادي و

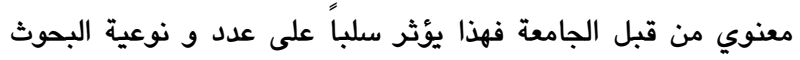

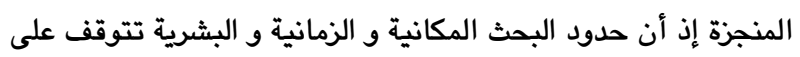
الامكانات المادية للباحث. وإن التنسيق الضعيف بين جامعتنا و الجامعات العالمية المتطورة تعد مشكلة أخرى في سبيل إنجاز البحوث التربوية لأنها لا تعطي مجال للباحث للتعرف على التطورات الحاصلة في مجال مناهج و إجراءات البحث و غيرما في الجامعات الاخرى و تمكنه من التعرف على انظمة و

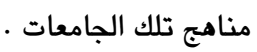
ومن المشكلات الاخرى التي تعرقل الباحث لإنجاز البحوث مي قلة عقد المؤتمرات في جامعتنا و كذلك عدم وجود مختبرات خاصة للتخصصات النفسية و التربوية تمكن الباحث من إجراء بحوث تجريبية ذو مستوى وجى عالِ من الدقة و العلمية ترتقي الى مستوى البحوث المنجزة في الجامعات العالمية و مذا يؤثر سلباً على دافعية الباحث. و من الاسباب الاخرى التي لا تشجع الباحث على إنجاز البحوث هي ان عدد البحوث المنجزة

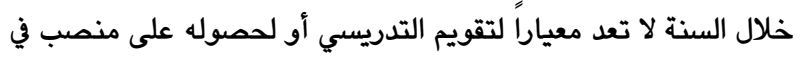
الجامعة مما يرسخ في ذمنه فكرة أنه ما من أهمية لإنجاز البحوث كوسيلة لتحقيق طموحاته الاكاديمية. و للبحث الجماعي أهمية بالغة للباحث حيث تمكنه من العمل مع باحثين آخرين و الاستفادة من خبراتهم وتقليل عبئ إجراءات البحث عليه و يبدوا أن عدم تشجيع قيام فريق البحث الجماعي هي الاخرى من المشكلات التي يعاني منها الباحث التربوي في جامعة دهوك وتمثل ما تم ذكره من المشكلات العشرة الاولى ذات الاوزان المئوية الاعلى.

\begin{tabular}{|c|c|c|c|}
\hline الفترة الزمنية & عدد البحوث المنجزة & نسبة الباحثين & \\
\hline طيلة خدمته في الجامعة & صفر & $\% 41,3$ & .1 \\
\hline خلال السنة & 1 & $\% 41,3$ & .2 \\
\hline خلال السنة & 2 & $\% 17,4$ & .3 \\
\hline
\end{tabular}


2. وجود ضعف في مستوى انجاز البحث التربوي والنفسي بشكل عام

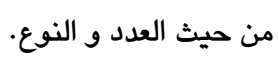

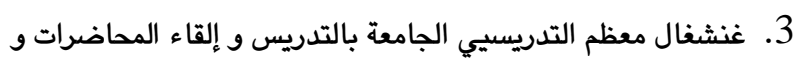
العمل على توفر مستلزمات المعيشة اكثر من انجاز البحوث في المجال التربوي بشكل خاص.

4. إنجاز البحوث التربوية لدى معظم الباحثين كانت لغرض الترقية

5. اهتمام الجامعة بالبحوث العلمية للعلوم الصرفة اكثر من البحوث

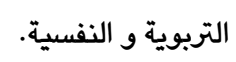

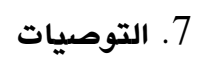

في ضوء نتائج البحث واستنتاجاته خرج الباحثان بالتوصيات الاتية:

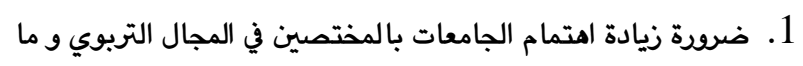
ينجزون من أبحاث عن المتغيرات و المشكلات التربوية و النفسية

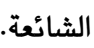

2. اصدار مجلة متخصصة لنشر الابحاث و الدراسات التربوية بشكل

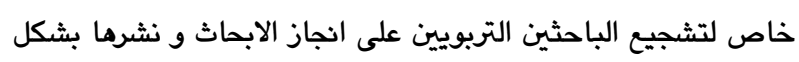

سريح.

3. زيادة وعي التدريسيين في المجال التربوي في منهجية وإجراءات البحث التربوي عن طريق اشراكهم في دورات عن متطلبات و اجراءات

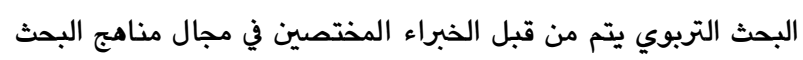

$$
\text { التربوي والإحصاء و القياس و التقويم . }
$$

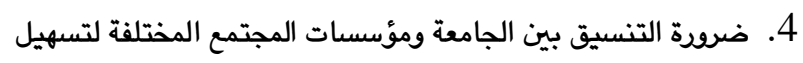

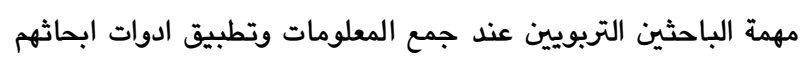

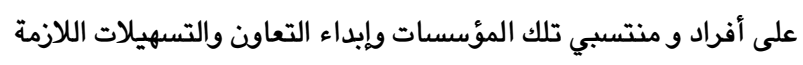

5. ضرورة الاستفادة من نتائج و استنتاجات و توصيات الابحاث

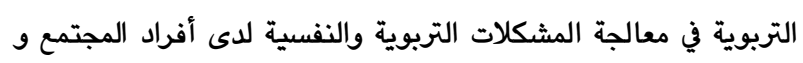

مؤسساتها.

6. تشجيع التدريسيين للمشاركة في المؤتمرات و الندوات العلمية بأبحاث تربوية في داخل و خارج إقليم كوردستان و تقديم التسهيلات

اللازمة لمشاركتهم في تلك المؤتمرات من قبل الجامعة و الوزارة .

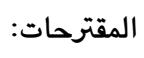

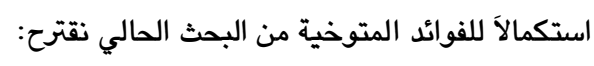

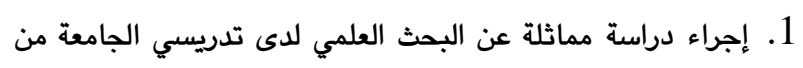

الاختصاصات العلمية الاخرى.

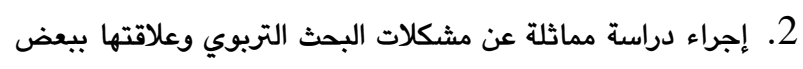
المتغيرات مثل الجنس و المرتبة العلمية و التخصص و و الحالة الاجتماعية للتدريسي ...الخ الخئ
ويظهر من بيانات الجدول أعلاه عن وجود ضعف في مستوى إنجاز

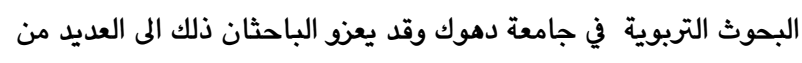
المشكلات و العقبات التي تواجه الباحثين و التي ذكرت آنتاً. هذه النتيجة من نتيجة دراسة الكبيسي و الراوي (2010) حيث أظهرت تدني مستوى الانجاز العلمي لأعضاء هيئة التدريس في الجامعة بشكل

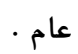

3.5. بالنسبة للهدف الثالث المتعلق ب) التعرف على مستوى

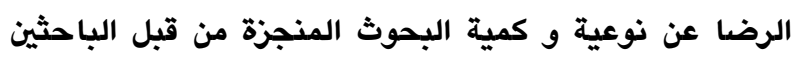
التربويين): أظهرت نتائج البحث بالنسبة لهذا الهدف ان نسبة 53٪ من الباحثين

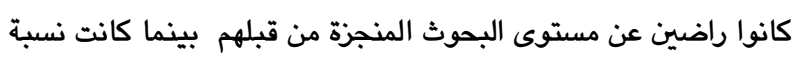

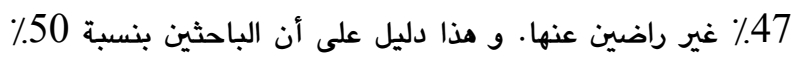

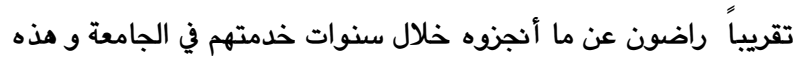
النسبة لا تصل الى مستوى الطموح في ظل العولمة و النفجار المعرفي

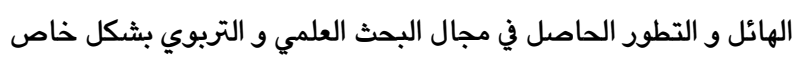

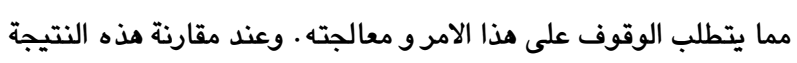
مع نتائج الدراسات السابقة يظهر تفرد البحث الحالي بهذه النتيجة.

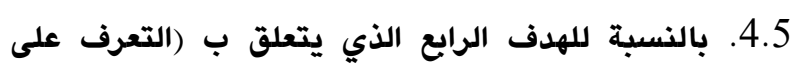

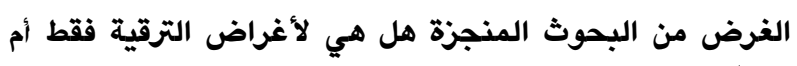

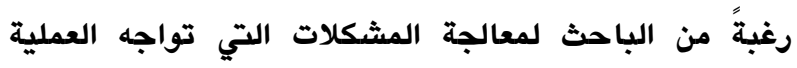
التربوية): أظهرت النتائج عن وجود نسبة 63٪ من اللتدريسيين قد أنجزوا البحوث

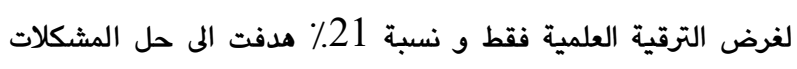

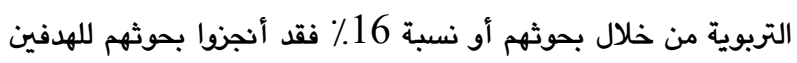

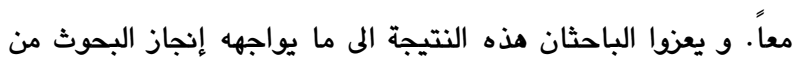
عقبات و معوقات ذكرت كلها في نتائج الهدف الاول وخاصة كما ذكر في الي

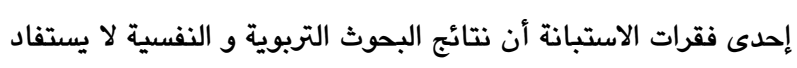

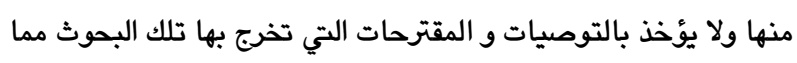
يؤدي الى ضعف الدافعية لدى معظم الباحثين في إقليم كوردستان العراق

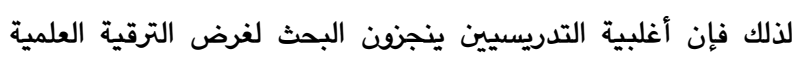

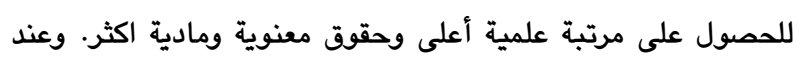
مقارنة هذه النتيجة مع نتائج الدراسات السابقة يظهر تفرد البحث الحالي

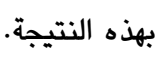

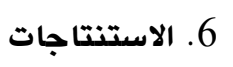
في ضوء نتائج البحث يمكن الخروج بالاستنتاجات الاتية :

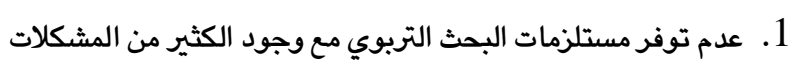
التي تواجه الباحثين في مجال البحث التربوي في الجامعة. 


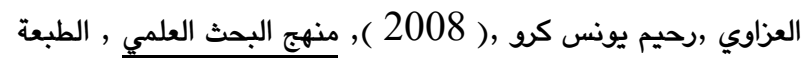
الاولى ,دار دجلة , المملكة الاردنية الهاشمية.

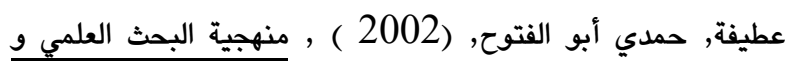

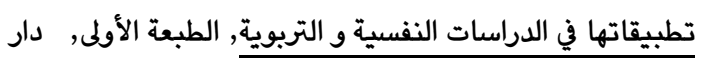
النشر للجامعات, القاهرة رمصر .

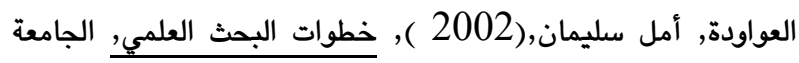
الاردنية, مكتب خدمة المجتمع, عمان, الاردن الكبيسي , عبدالواحد وحميد و الراوي ,عادل صالح,( 2010), الاتتاج العلمي لأعضاء هيئة التدريس في جامعة الانبار من البحوث العادي

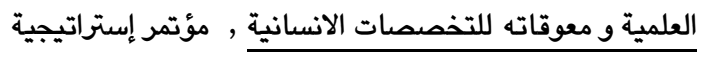
البحث العلمي في الوطن العربي ربغداد ,كلية التربية للبنات .

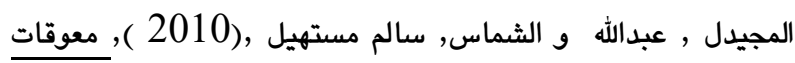
البحث العلمي في كليات التربية من وجهة نظر أعضاء الهيئة التدريسية , مجلة جامعة دمشق , المجلد 26, العدد (1,2) . محسن , منتهى عبدالزهرة , (2011 ), الصعوبات التي تواجه البحث

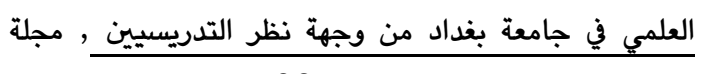
البحوث التربوية و النفسية, العدد 32 البغد

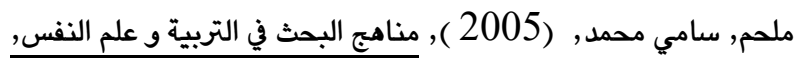
الطبعة الثالثة ,دار المسيرة, عمان الأردن.

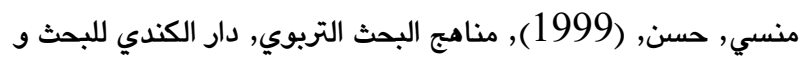
النشر , أربد.

UNESCO science report,2010, UNESCO publishing
3. اجراء دراسة مقارنة عن مستوى انجاز البحوث التربوية في جامعة دهوك مع الجامعات الاخرى في الاقليم.

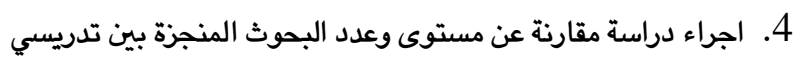
الجامعات الحكومية والأهلية في الاقليم.

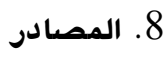

$$
\begin{aligned}
& \text { إبراهيم,محمد عبد الرزاق و أبو زيد ,عبد الباقي عبد المنعم, }
\end{aligned}
$$

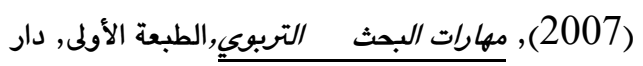

$$
\begin{aligned}
& \text { الفكر, عمان الأردن. }
\end{aligned}
$$

البرغوثي ,عماد أحمد و أبو سمرة ,محمود أحمد , (2007), الاردن.

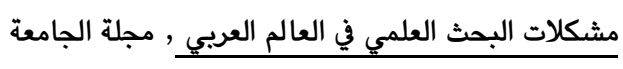

الاسلامية , المجلد 5 ,العدد 2, جامعة القدس ,فلسطين .

الجرجاوي , زياد علي و حماد ,شريف علي , (2005), معوقات

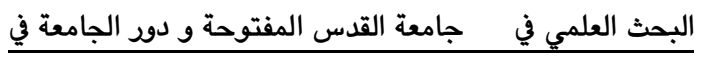

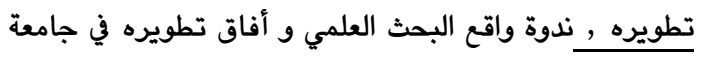
القدس المفتوحة.

حمدي, محمود مظلوم , ( 1995),طرق الاحصاء , ر دار المعرفة,الاسكندرية ,مصر مصلوم

الخطيب ,أحمد (2003 ), البحث العلمي و التعليم العالي , الطبعة

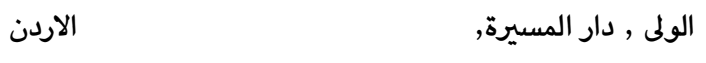

عبدالحميد, محمد, (2000) ,البحث العلمي في الدراسات الإعلامية, بيروت ,عالم الكتاب.

عدس,عبدالحمن, (1996) , أساسيات البحث التربوي, الطبعة الثانية, دار الفرقان للطباعة و النشر, أربد. 


\section{الملحق (1)}

أسماء الخبراء الذين تم الاستعانة بهم

\begin{tabular}{|c|c|c|c|}
\hline الكلية و القسم & اللقب العلمي & 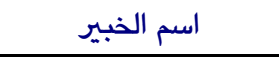 & $ت$ \\
\hline كلية التربية الاساسية /علم النفس & أستاذ & د. مولود حمه نبي & .1 \\
\hline كلية التربية الاساسية /علم النفس & 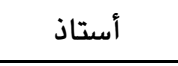 & د. فاتح أبلحد فتوحي & .2 \\
\hline كلية التربية الأساسية /التربية الخاصة & أستاذ مساعد & د. جاجان جمعة محمد & .3 \\
\hline كلية التربية الاساسية /علم النفس & أستاذ مساعد & د.محمد سعيد محمد & .4 \\
\hline كلية التربية الاساسية /علم النفس & أستاذ مساعد & د.نالان جميل إبراهيم & .5 \\
\hline كلية التربية الأساسية /الاجتماعيات & أستاذ مساعد & د. محمد سعيد برواري & .6 \\
\hline كلية التربية الأساسية /رياض الأطفال & 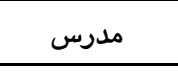 & 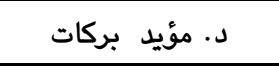 & .7 \\
\hline كلية التربية الأساسية /التربية الخاصة & 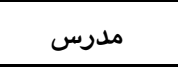 & د. أحلام محمد طامر & .8 \\
\hline كلية التربية الأساسية /اللغة الانجليزية & 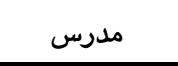 & د. أسماء يحيى قاسم & .9 \\
\hline
\end{tabular}

الملحق (2)

كلية التربية الاساسية

وحدة البحوث التربوية

استمارة مشكلات البحث التربوي بصيغتها النهائية

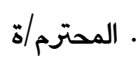
حضرة التدريسي/ة. تحية طيبة ...

في النية القيام بدراسة عن (واقع البحث التربوي ومشكلاتهة من وجهة نظر التدريسيين التربويين في جامعة دهوك) .و لتحقيق اهداف البحث تم اعداد اداة على شكل استبانة من النوع (المغلق المفتوح)مؤلفة من (26) فقرة تعبر كل منها عن مشكلة من المشكلات التي تواجه الباحثين في المجال التربوي تليها ثلاثة اسئلة مفتوحة اخرى, و لغرض بيان حدة أو قوة كل مشكلة من تلك المشكلات نرجو بيان رأيك من خلال وضع علامة (ل) تحت البديل المناسب أمام كل فقرة لغرض الخرجج بنتائج وتوصيات لازمة لمعالجة تلك المشكلات و الاجابة بكل حرية و صراحة عن الاسئلة الثلاثة الاخرى التي تلي الفقرات .

مع فائق التقدير

م. بشكوش جعفر عبدالله أ.د. صابر عبدالله زيباري مدرسة في كلية التربية الاساسية مدير مركز البحوث التربوية

\begin{tabular}{|c|c|c|c|c|}
\hline مشكلة ثانوية & مشكلة متوسطة & مشكلة كبيرة & الفقرات (المشكلات) & ت \\
\hline
\end{tabular}




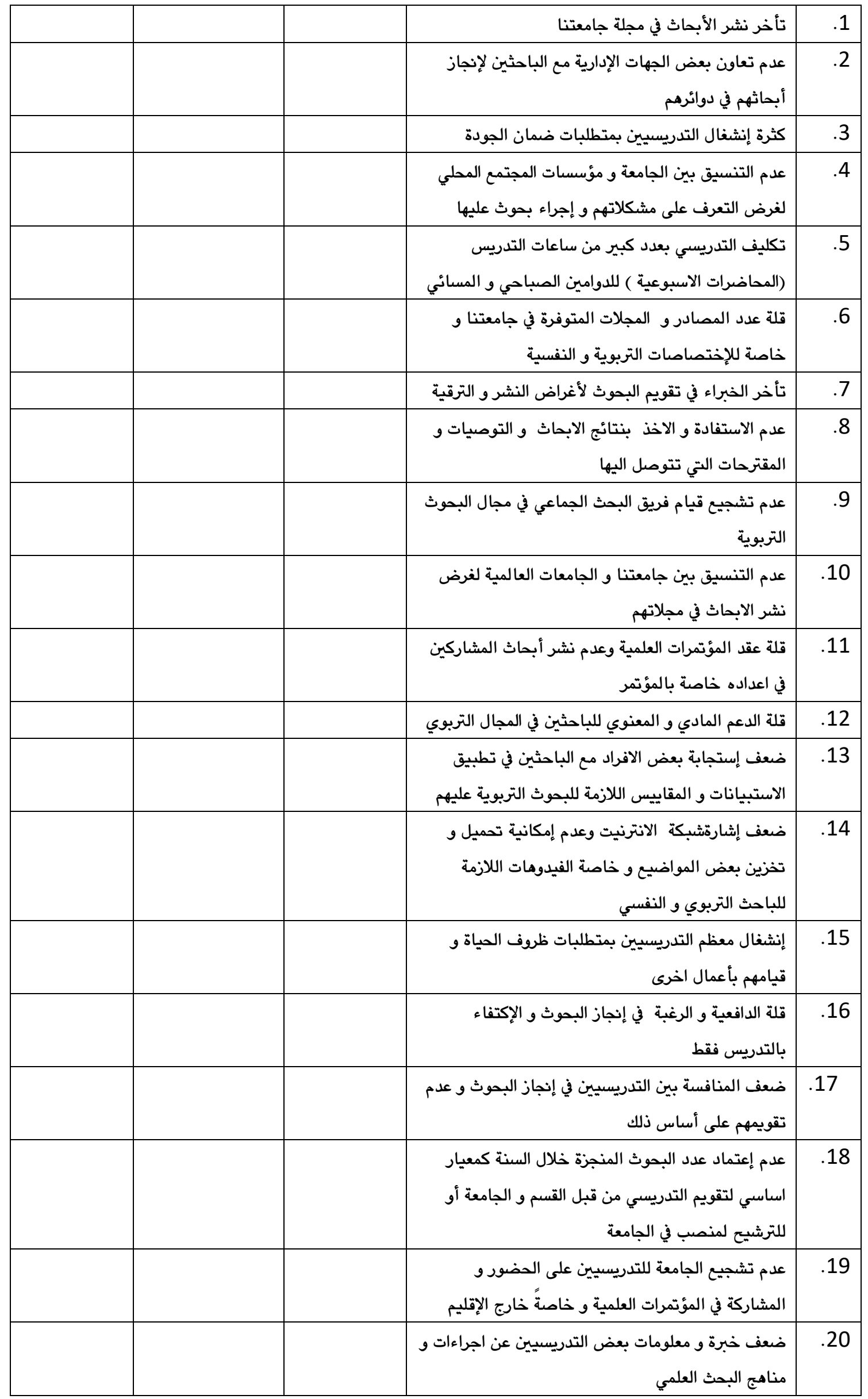


سعيد، صابر عبد الله و عبدالله، بشكوش جعفر / مجلة العلوم الانسانية لجامعة زاخو، مجلد:6 ، العدد:3 ، ص 837- 849، ئيلون- 2018.

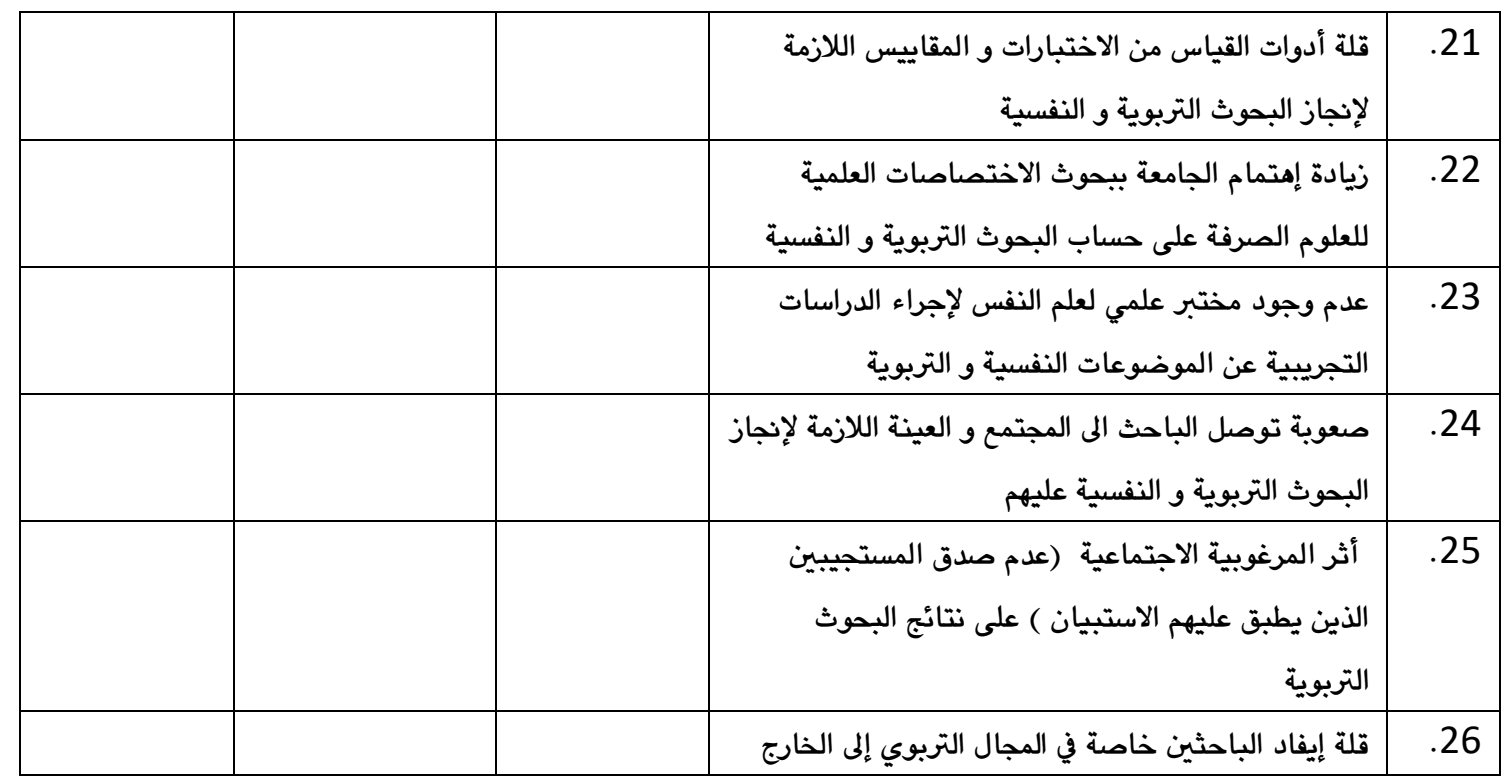

والان نرجوا شاكراً الاجابة بكل حرية وصراحة على الاسئلة الاتية:

س1 /كم بحثاً قد انجزته في مجال اختصاصك خلال عملك كمدرس جامعي؟

س2 /هل انت راض عن مستوى ونوعية البحوثالمنجزة من قبلك في مجال اختصاصك ؟

س3 / هل ان هدفك من إجراء البحوث التربوية و النفسية هو لأغراض الترقية فقط أم رغبة منك لمعالجة المشكلات التي تواجه العملية التربوية وغيرها؟ 


\section{The Reality of Educational Research and its Problems from the Point of View of Educational Teachers at the University of Duhok $\square$}

\section{Abstract: $\square$}

The current research aims to identify the following:

The most important problems faced by educational researchers at the University of Dohuk.

1. The percentage of research carried out by educational researchers during their period of teaching.

2. The level of satisfaction of educational researchers on their completed research.

3. The purpose (objective) of the completion of research (whether it is for scientific promotion only or a desire to solve the problems facing educational field and others).

In order to achieve the objectives of the research, the descriptive method was followed. The tool of the research consists of an open closed questionnaire consisting of (26) paragraphs each one of them expresses a problem of the researcher's problems in educational research with four open questions followed by those paragraphs and was applied on a sample of (43) teachers in the departments of the Faculty of Basic Education and Sport at the University of Dohuk.

After the analysis of the data statistically by using Fisher equation to extract the strength of the paragraphs, the results showed that all the paragraphs of the questionnaire formed problems that are obstacles to educational researchers so it was found that the rate of completion of research was very low, it was found that $41.3 \%$ of the teachers did not perform any research, $41.3 \%$ completed one research per year, $17.2 \%$ completed two research projects during the year. It was also found that $53 \%$ were satisfied with their level of achievement and $47 \%$ were dissatisfied. As for the purpose of the research, $63 \%$ had completed the research with a desire to solve educational problems and 16\% were intended for both. Finally, the researchers came up with a set of recommendations and suggestions for the purpose of promoting the level of achievement of educational research at the University of Dohuk.

Keywords: educational researchers, Educational Research, University of Duhok.

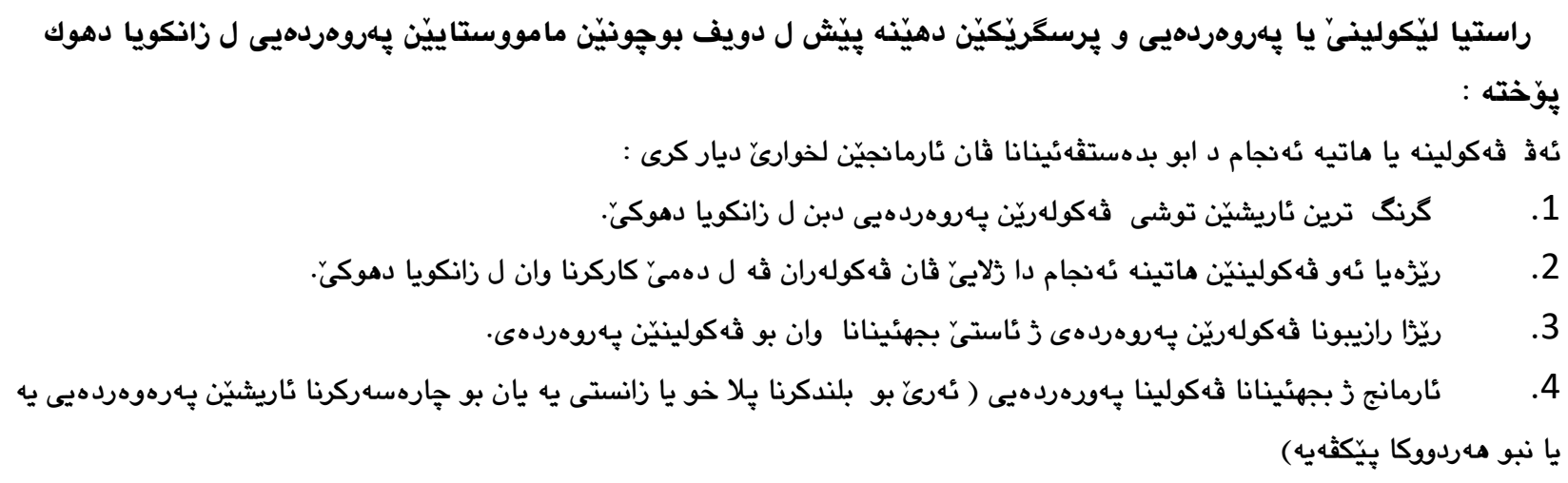

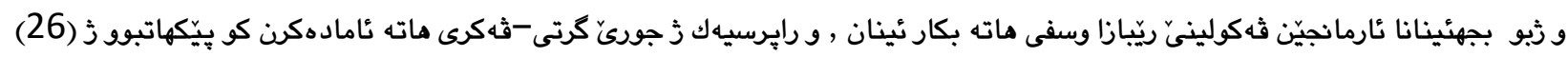

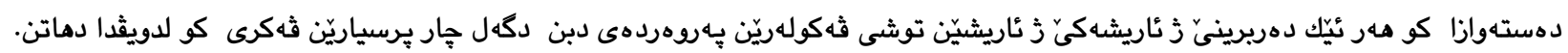

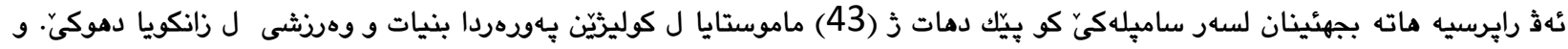

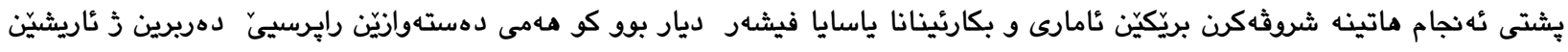

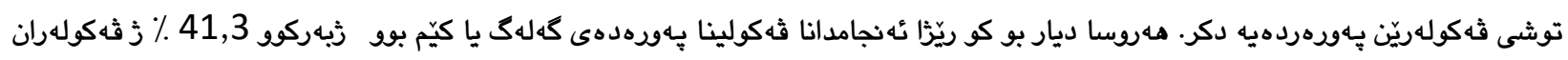

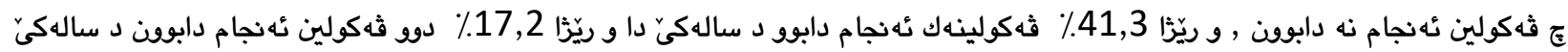

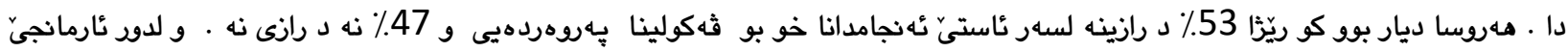

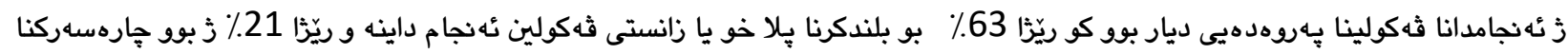

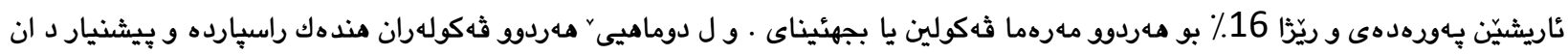
بو بلندكرنا ئاستى بجهئينانا ثهولينا پِهروهردهيى ل زانكويا دهوكيّ دان.

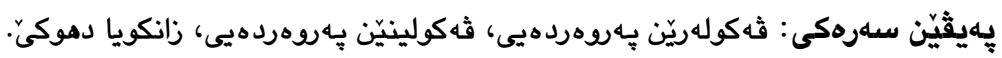

